\title{
Flinders University School of Medicine, Northern Territory, Australia: Achieving Educational Excellence along with a Sustainable Rural Medical Workforce
}

\author{
Paul Worley, MBBS, PhD, FACRRM, FRACGP, DObstRANZCOG
}

\begin{abstract}
Introduction Medical schools today are being challenged to educate doctors who are willing and able to practice in areas of poverty and workforce need. In many countries, there is a shortage of doctors practicing in rural and remote communities. There is evidence that locating undergraduate medical education in rural areas increases the likelihood that graduates will choose to practice in underserved areas. Through its Parallel Rural Community Curriculum (PRCC), Flinders University School of Medicine (FUSM) now enables over 25\% of its students to undertake an entire clinical year based in small rural communities supervised principally by rural family physicians.
\end{abstract}

Objective The PRCC was conceived to provide a high quality educational intervention that would result in an increased number of students choosing to practice in rural and remote Australia. It was also designed to test the hypothesis that small rural and remote practices were capable of facilitating a full year of medical training at a standard comparable to that provided at a major tertiary hospital.

Intervention Starting with eight students in four towns in 1997, the PRCC now places 30 students across 18 towns in rural Australia. The

"No matter how far a country may advance in medical science, if that science be available to only a select few, that country cannot take pride in its medical progress."

- Ruzumoski, 1905

\section{INTRODUCTION}

In Australia, as in most countries of the world, there is a significant disparity in health outcomes between those who live in major cities and those who live in rural and remote regions:[1] the more remote, the greater the disparity and lower the proportion of doctors in relation to the population. While $33 \%$ of Australia's population lives outside the metropolitan centers, only $20 \%$ of its doctors work there.[2] At the same time, medical schools are challenged to be accountable to the communities they serve, regardless of their demographics.[3] To meet this challenge, the Flinders University School of Medicine (FUSM) developed a strategic response to Australia's rural medical workforce crisis based upon four streams of evidence.

\section{The Four Streams}

First, there is clear evidence that increasing the number of rural origin students admitted to medical school, combined with provision of high quality rural experiences during undergraduate education, increases the percentage of graduates who will choose to practice in a rural or remote community. $[4,5]$ In particular, there is accumulating evidence that longer rural exposure in the latter years of training is a more effective intervention.[6] Thus, reviewing selection processes to reverse any discrimination against students simultaneously learn the disciplines of medicine, surgery, pediatrics, obstetrics and gynecology, psychiatry, and family medicine. At the end of the year, all Flinders students, regardless of training location, take the same comprehensive exam.

Outcomes PRCC students improved their academic performance in comparison to their tertiary trained peers. This improvement has been consistent over the ten years studied. Seventy percent of the PRCC students have chosen to practice in rural locations, compared to 18 percent of tertiary-trained students. Over twelve years, the program has proved to be sustainable in a private practice environment with a workforce shortage.

Conclusions Evaluation of the PRCC indicates that a rural community-based clinical education can provide a high quality academic experience for students as well as a sustainable solution to rural medical workforce maldistribution.

Keywords: Community-based medical education, CBME, communityoriented medical education, COME, rural medical workforce, Australia

rural origin students, along with moving substantial components of clinical education into rural locations, is a responsible, evidencebased approach. But what form should this medical education take? This requires further evidence from the other streams.

The second stream of evidence is changes occurring in medical education, particularly a demand for medical curricula that are relevant to the priority health needs of the community in which graduating doctors will be placed, and for those graduates to be generalists, skilled at working in inter-professional teams and capable of undertaking further education in any medical specialty. [7] The response to these imperatives has been described as Community-Oriented Medical Education (COME).[8]

The third stream refers to changes in medical practice over the last two decades. As hospitals have become more specialty-driven, teaching medical students in such institutions has become more difficult. Patients are often discharged rapidly, and the case-mix has become less relevant to the broad areas required by undergraduate medical education.[9] Additional evidence is provided by White's research, which showed that only $1 \%$ of the spectrum of illness in a community is actually treated in a major tertiary hospital. [10] If medical students are to see the common diseases afflicting populations, then medical education must move to where the patients are - into the community. These forces have led to what is known as Community-Based Medical Education (CBME).[11]

Taken together, these three streams would suggest that the best evidence-based response for a medical school confronted by 
Australia's rural health disparity would be to increase rural admissions and reorient the curriculum to meet the rural community's needs through Community-Based Medical Education.[12] But a fourth stream adds even more weight and refinement to this approach: the field of medical research.

Increasing calls for evidence-based clinical practice[13] create a dilemma for rural and remote clinicians. Most of the 'evidence' is collected in urban tertiary hospital environments where most clinical researchers conduct their work. It is questionable, however, whether this evidence is necessarily relevant to best practices in resource-poor, geographically isolated settings. A context-specific evidence base needs to be developed, which requires an academic infrastructure in rural and remote communities. Therefore, rural Community-Based Medical Education should be led by clinical academics working in rural and remote communities, with time and resources to build an appropriate research infrastructure in these locations. $[14,15]$

\section{The Flinders Initiatives}

Flinders University has incorporated these four streams into its strategic response to Australia's rural medical workforce crisis. The Flinders University School of Medicine began in 1974 as the teaching and research arm of Flinders Medical Centre (FMC) in Adelaide, South Australia, now part of the Southern Adelaide Health Service (SAHS).

This was the first time in Australia that a new medical school and a new tertiary hospital were built together on a university campus. With teaching, research, and clinical services all located in one building, the founders envisioned Flinders as a research center of excellence in both the biomedical and social sciences, combined with an innovative, integrated approach to

Figure 1: Flinders School of Medicine Campuses Across Australia

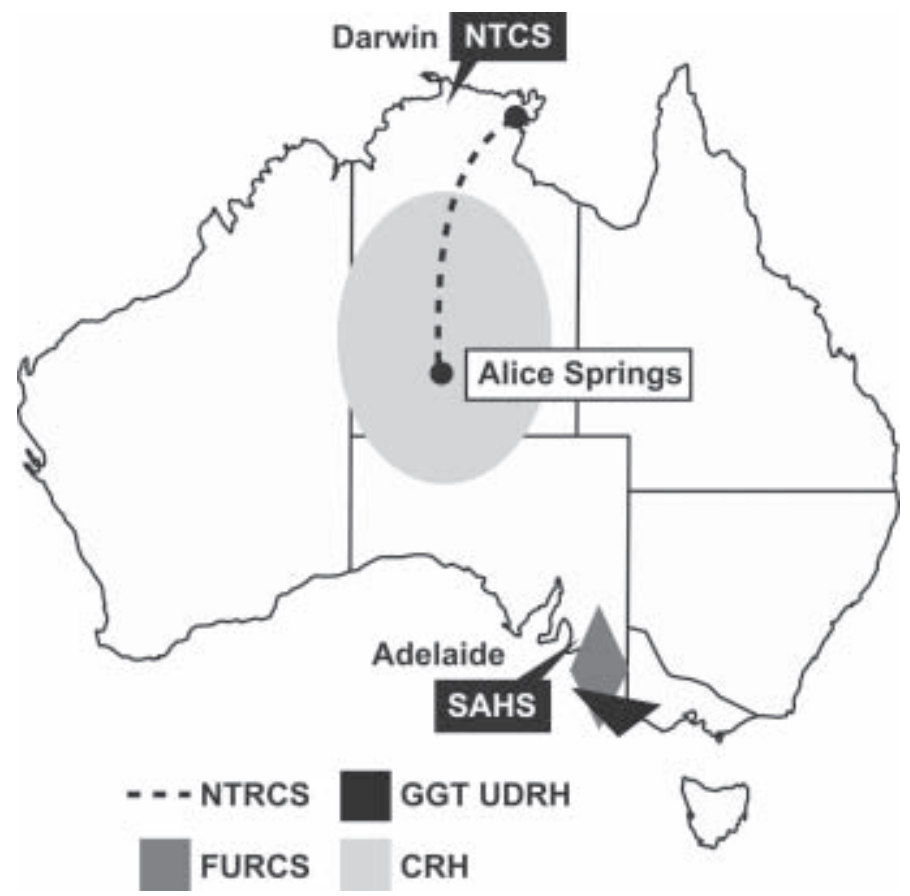

teaching. In 1996, it was the first Australian medical school to move from the traditional six-year high school entry program to a four-year graduate-entry medical program that now accepts 135 students per year. The FUSM has also developed a large number of other health professional courses.

During the 1990s, in partnership with targeted funding initiatives of the Australian Government, FUSM developed a significant and expanding rural and remote presence with clinical training and research activities in remote regions of Australia. It now has five academic units explicitly targeting the rural medical workforce crisis (Figure 1).

1. The Centre for Remote Health $(\mathrm{CRH})$, based in Alice Springs and Katherine in the Northern Territory, offers Masters Degree programs in Remote Health Practice and Remote Health Management. $\mathrm{CRH}$ has also established a rural and remote health services research program that has informed national policy and advocacy efforts.

2. The Greater Green Triangle University Department of Rural Health (GGT UDRH) is based in Warrnambool, Victoria. Its rural cardiovascular and diabetes risk factor studies are linked to groundbreaking public health work in Finland, and their work on the association between diabetes, heart disease, and depression has prompted national health workforce development in this field.

3. The Northern Territory Clinical School (NTCS) based in Darwin has provided the foundation for medical education in the Northern Territory. NTCS has been teaching thirdand fourth-year medical students in the NT since 1998. It is recognized for its high-quality cultural awareness training in Indigenous health and has been credited for overcoming problems recruiting interns and senior staff at Royal Darwin Hospital.[16]

4. The Flinders University Rural Clinical School (FURCS), with headquarters in Renmark, South Australia, has pioneered rural community-based medical education in Australia through its Parallel Rural Community Curriculum (PRCC).[17] This program, with academic leadership from experienced rural clinicians, enables senior medical students to undertake their principal clinical year based in a small rural community. The PRCC successfully functions in a private, fee-for-service funding environment with workforce shortages in practices and health services.

5. The Northern Territory Rural Clinical School (NTRCS) has augmented the NTCS by introducing six-month communitybased clinical attachments in the remote communities of Katherine, Alice Springs and Gove. These placements, developed from the PRCC model, have been created by forming significant partnerships with all health services in the region, including Aboriginal Medical Services. The NTRCS has been innovative in its use of Information Technology to enable communication between remote students and specialty teachers in Darwin and Adelaide.

The Northern Territory Government Department of Health and Community Services provides considerable support for the NTCS. The other four units are a funded initiative of the Australian Government Department of Health and Aging. 
Figure 2: Conceptual Framework of the Flinders Parallel Rural Community Curriculum (PRCC)

Year 3 Flinders Medical Center

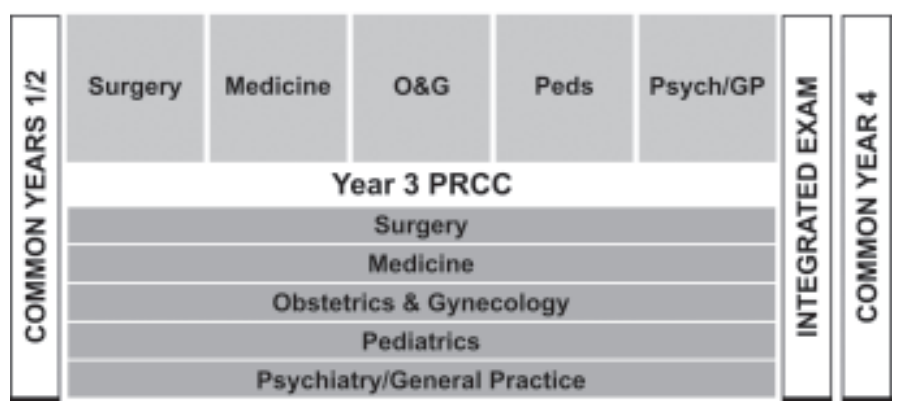

\section{INTERVENTION}

The Flinders Parallel Rural Community Curriculum (PRCC) FUSM introduced this longitudinal integrated curriculum in $1997,[18]$ challenging the longstanding dogma that clinical medicine is best learned in a series of focused rotations. The PRCC's primary innovation is based on the recognition that the required variety of pediatrics cases, for example, will not be seen in a sixweek rotation in a rural practice, but that over the whole year this can easily be achieved. The same is true for each of the disciplines. Thus, the curriculum map was rotated 90 degrees, but the relative weightings of the disciplines remained the same (Figure 2).

Students choose to spend their entire Year 3 (out of a four-year graduate-entry medical program) based in a small rural town. Currently, 30 students per year are placed across 18 towns, ranging from 4,000 to 20,000 in population. An additional eight students per year undertake the half-year option in the Northern Territory.

Students in the PRCC program study all the clinical disciplines simultaneously, based on 'what walks through the door'. Careful site selection ensures that the epidemiology of the practice's patient mix will match the curriculum requirements. Students can log their experience against a list of over 100 medical problems, covering all disciplines, for which they must demonstrate competency in their Year 3 assessments. They receive supervision and feedback from doctors in their designated rural practice throughout the year.

Each regional group of between four and six practices (ranging from four to twenty doctors per practice) also has a designated academic coordinator. This person is a locally practicing clinician who provides a link between the University and the local practices. Based on feedback from doctors in these practices, the academic coordinator can modify the students' weekly program to ensure a balanced experience. At the end of the year, PRCC students sit the same exam as their hospital-trained peers.

PRCC students are provided with accommodation (with their families, if required) and become part of the community for that year. They also become part of the health care team. They meet their patients in the local family practice and follow them through all their care venues - hospital admission, specialist consultations and procedures, allied health interventions, and follow-up visits with the rural family doctor. It is a very hands-on learning environment, mentored and facilitated by the rural doctors, providing longitudinal access to patients with common problems reflective of both the national health priorities and the Flinders curriculum.

In each practice, the university identifies one doctor as the principal supervisor for the students. This doctor must have the support of his or her colleagues, along with well-developed skills for facilitating learning, giving feedback, and providing pastoral care for the students. Supervisors receive support to further develop their educational skills by completing the university's Graduate Certificate in Clinical Education.

There has been significant support from clinical and administrative staff of local hospitals,[19] which range in size from a daily bed occupancy of between six and fifty patients. Some have resident generalist specialists, but most are staffed by local primary care doctors with only a visiting specialist service. Students are welcomed into these facilities and have excellent access to all clinical activities. Flinders has partnered with the hospitals to improve educational and study facilities within these health services for use by students and staff.

Another important innovation is the use of information and communication technologies, such as videoconferencing and webbased teaching resources, to link this excellent learning environment with the sub-specialist expertise available in the urban tertiary hospital, thus providing students with the best of both worlds.

\section{OUTCOMES}

A research program was designed to assess the educational quality, workforce outcomes, and sustainability of the PRCC. A variety of methods were chosen, each appropriate to the particular focus of enquiry.

Figure 3: Improvement in Student Exam Scores from Year 2 to Year 3. Comparison of PRCC Students with Students at Flinders Medical Centre (FMC) and Northern Territory Clinical School (NTCS) from 1998 to $2005(n=636)$

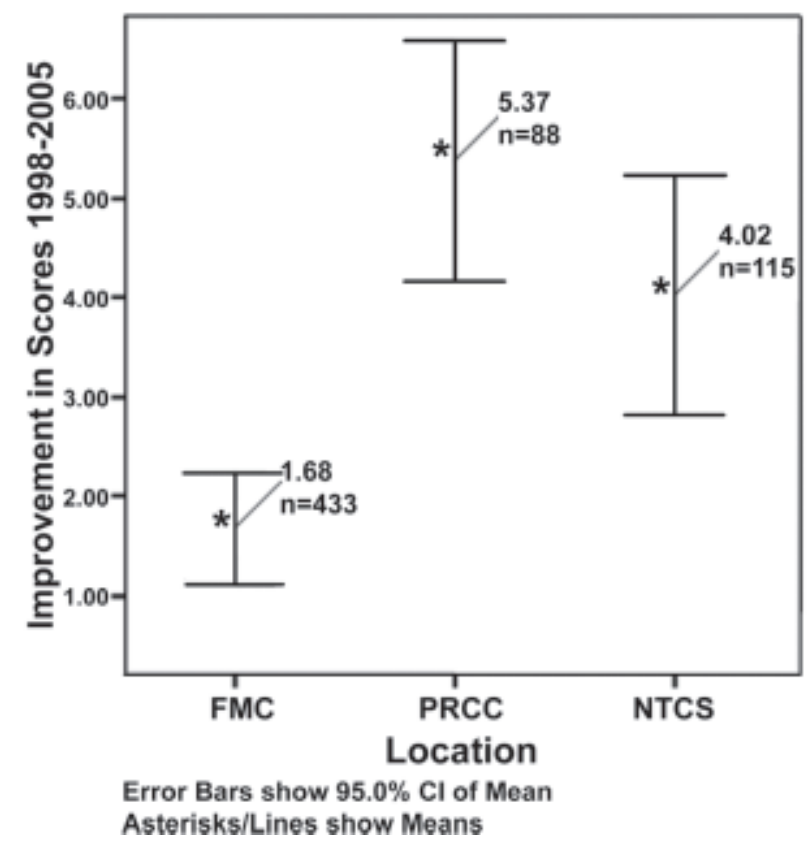




\section{Academic Results}

All medical students at FUSM take their major clinical examination at the end of Year 3, no matter where they trained during the year. Prior to choosing either the PRCC, the NTCS in Darwin, or the conventional tertiary hospital track at FMC in Adelaide, all students have completed a two-year problem-based learning curriculum together in Adelaide. Their academic results at the end of Year 2 are collated and later compared with their results at the end of Year 3, providing a measure of the academic impact of the PRCC intervention.

The academic results have been very encouraging (Figure 3 ). Improvement in the examination performance of PRCC students has been consistent when accounting for the different cohorts over the years and for differences in age and sex.[20] Further research has revealed aspects of the curriculum that may help explain why this improvement has been sustained. In comparison to their tertiary hospital-trained peers, PRCC students have greater clinical contact and spend more time in clinical settings; they have greater exposure to common conditions; and express greater satisfaction with their clinical learning.[21,22] They describe a different quality to their learning environment, referring to themselves as 'going to work', rather than 'going to university'.[23]

\section{Workforce Outcomes}

Evidence for the workforce effectiveness of the PRCC was sought once the first three cohorts were at least five years post graduation and thus were either in, or had completed, their specialty training.[24] A postal survey of these students in 2005 achieved a $46 \%(n=13)$ response rate. Analysis revealed that approximately $70 \%(9 / 13)$ of PRCC graduates are practicing in rural communities, $62 \%(8 / 13)$ specializing in primary care. This compares with $18 \%(8 / 45)$ of tertiary hospital-trained students choosing rural practice, and $38 \%(15 / 40)$ choosing primary care. The differences in preference for rural practice persisted after accounting for rural background, age, and sex.

\section{Sustainability}

The last of our three pre-eminent issues was sustainability, particularly sustained involvement of the rural doctors. Sustainability in an environment of workforce shortage was not taken for granted. Would the practices continue to commit to the program over an extended period? Would the loss of key doctors from the region over time compromise the program? Would students continue to volunteer for the program and would they continue to perform at a high academic level?

A continuous quality improvement approach was used to address these questions, with regular meetings, interviews and focus groups involving academic staff, students, rural clinicians and other participants, to plan and review the progress and outcomes of the program. We have found that practices have continued to commit enthusiastically to the program. The number of both practices and students involved in the PRCC has increased by $400 \%$ over the past twelve years. Students have continued to oversubscribe the program. Those interested are given the opportunity to visit the regions early in their course, and frank peer-to-peer feedback from previous participants is encouraged. In addition, the continued academic excellence of students in the program has been a major 'selling' factor. We now have students who choose to study medicine at Flinders because they want to undertake our rural and remote programs, and we also have past students as faculty in our teaching practices.

An initial concern of the practices was whether they would suffer a decrease in income due to seeing fewer patients when supervising students. In this regard, we learned early in the program that it was important that the student, when consulting in the practice, had access to a separate consulting room. This additional room enabled the supervisor to see patients in parallel with the student, yet still provide effective supervision and teaching. This required considerable investment in building or modifying consulting rooms in the private practices, with capital funding provided by the Australian Government. A recent study at one of our PRCC sites showed that, when using this parallel consulting method, there was no increase in the time taken by the doctor to see patients.[25] Therefore, there was no lengthening of the consulting session, and no decrease in income from the session.

\section{DISCUSSION}

Australia, through the policies of its national government, has clearly asked for solutions to the maldistribution of physicians. Flinders' transformation from an urban, high resource, tertiary teaching setting to the most distributed medical school in Australia, teaching in under-resourced rural and remote settings, is an example of social accountability. Understanding how this change has occurred is a fertile field for further research.

A challenge now is to translate this approach to urban underserved areas. A six-month version of this program was piloted in Darwin in 2008, and a full-year PRCC program will commence in 2009 in the southern area of Adelaide. Other schools around the world are now using community-based and communityoriented principles, including one in Canada that is using the PRCC approach for its entire class.[26]

The workforce outcomes are particularly encouraging. Not only do they confirm the effectiveness of the PRCC approach as a rural workforce strategy, but they also reassure Flinders that this program is not just about producing rural primary care doctors. Graduates are qualified for selection into postgraduate specialty training in a wide variety of disciplines. Further research is being undertaken to clarify when and how the graduates make their career decisions. These studies will hopefully help us understand to what extent the PRCC is confirming existing interest in rural medicine and how often it is converting an urban skeptic. Additional research will investigate why graduates are choosing rural practice, although not necessarily the rural practice in which they trained. This is a particularly important question for the supervising doctors who are investing their time in this program.

Further analysis of the data obtained from interviews with the students has led to the development of a conceptual model that uses the concept of symbiosis, where the presence of the student adds value to all the stakeholders in the clinical education system - patients and clinicians, health services and universities, governments and communities.[23] Further research is underway looking at the specific impacts on, and influences of, all contributors to this educational system. 
Given the demonstrated benefits to the university, the health system, students, and the community,[27,28] FUSM is challenging itself to develop new ways of increasing its medical education presence in disadvantaged remote Indigenous communities, particularly ways of constructing the program to attract and retain more Indigenous students.

\section{CONCLUSIONS}

A longitudinal integrated clerkship can enable medical students to complete an entire clinical year based in rural primary care. Far from being a second class education, the evidence shows significant academic benefits for the student. Workforce outcomes also show this type of medical education to be a significant part of a sustainable so- lution to providing a stable rural medical workforce. These findings can bring hope to many resource-poor regions around the world. It is possible to conduct high quality medical education in such settings in a manner that will bring credit and recognition to the health service and attract graduates to practice in these areas.

Such initiatives challenge the established norms of both clinicians and universities, and some will be earlier adopters than others. Perhaps the resource-poor areas will lead the wealthier areas in the uptake of this new approach to medical education. The benefits that would accrue in such a scenario may help redress lack of equity in many other areas and bring us closer to health for all. -1 -

\section{REFERENCES}

1. Australian Institute of Health and Welfare. Australia's Health 2006. Canberra: AlHW; 2006.

2. Australian Institute of Health and Welfare. Medical Labour Force 2004. National Health Labour Force Series No. 38. Canberra: AlHW;2006

3. Kamien M, Boelen C, Heck JE. Measuring the social responsiveness of medical schools. Education for Health (Abingdon) 1999:(12):9-19.

4. Wilkinson D, Laven G, Pratt N, Beilby J. Impact of undergraduate and postgraduate rural training, and medical school entry criteria on rural practice among Australian general practitioners: national study of 2414 doctors. Med Educ. 2003;(37):809-14.

5. Rabinowitz HK, Diamond JJ, Markham FW, Paynter NP. Critical factors in designing programs to increase the supply and retention of rural primary care physicians. JAMA. 2001;(286):1041-8.

6. Denz-Penhey H, Shannon S, Murdoch JC, Newbury JW. Do benefits accrue from longer rotations for students in Rural Clinical Schools? Rural and Remote Health 5 [serial on the Internet]. 2005:414. Available from: http://rrh.deakin.edu.au.

7. General Medical Council Education Committee Tomorrow's Doctors: Recommendations on undergraduate medical education. London, UK: General Medical Council;1993.

8. Hamad B. Community-oriented medical education: what is it? Med Educ. 1991;(25):16-22.

9. Komesaroff PA. What is the future of the hospital system? Is the hospital obsolete? Med J Australia. 1997;(166):17-9.

10. White KL, Williams TF, Greenberg BG. The ecology of medical care. $\mathrm{N}$ Engl $\mathrm{J}$ Med. 1961;(265):885-92

11. Boaden N, Bligh J. Community-Based Medical Education. London: Arnold; 1999.

12. Worley PS, Prideaux DJ, Strasser RP, Silagy CA, Magarey JA. Why we should teach undergraduate medical students in rural communities. Med $\mathrm{J}$ Australia. 2000;(172):615-17.

13. Sackett DL, Rosenberg WMC, Gray JAM, Haynes RB, Richardson WS. Evidence based medicine: what it is and what it isn't. Br Med J. 1996;(312):71-2[3].

14. Humphreys JS, Lyle D, Wakerman J, Chalmers E, Wilkinson D, Walker J, et al. Roles and activities of the Commonwealth government university departments of rural health. Australian Journal of Rural Health. 2000;(8):120-33.

15. 15 DeWitt DE, McLean R, Newbury J, et al. Development of a common national questionnaire to evaluate student perceptions about the Australian Rural Clinical Schools Program. Rural and Remote Health 5 [serial on the Internet]. 2005 [cited 2008 Jul]; 486. Available from: http://www. rrh.org.au

16. McDonnel Smedts A, Lowe M. Clinical Training in the Top End: Impact of the Northern Territory Clinical School on the Territory's Health Workforce. Rural and Remote Health [serial on the Internet]. 2007 [cited 2008 July];723. Available from http://www.rrh.org.au

17. Worley P, Silagy C, Prideaux D, Newble D, Jones A. The Parallel Rural Community Curriculum: an integrated clinical curriculum based in rural general practice. Med Educ. 2000;(34):558-65.

18. Hirsh DA, Ogur B, Thibault GE, Cox M. "Continuity" as an organizing principle for clinical education reform. New Engl J Med. 2007;356(8):858-66.

19. Disisto $N$. Success through partnerships: a learning environment. Commonwealth Department of Health and Aging National Networks. 2000;(24):6,7,16

20. Worley P, Esterman A, Prideaux D. Cohort study of examination performance of undergraduate medical students learning in community settings. Br Med J. 2004;(328):207-9.

21. Worley P, Prideaux D, Strasser R, March R, Worley $\mathrm{E}$. What do medical students actually do on clinical rotations? Med Teach. 2004; 26(7):594-8.

22. Worley P, Strasser R, Prideaux D. Can medical students learn specialist disciplines based in rural practice: lessons from students' self reported experience and competence. Rural and Remote
Health 4 [serial on the Internet]. 2004 [cited 2008 Jul 21];338. Available from: http://www.rrh.org.au

23. Worley P, Prideaux D, Strasser R, Magarey A, March R. Empirical evidence for symbiosis medical education: a comparative analysis of community and tertiary-based programs. Med Educ. 2006;(40):109-16.

24. Worley P, Prideaux D, Woodman R, Worley E. Vocational Medical Career Paths of Graduate Entry Medical Students at Flinders University: a comparison of rural, remote and tertiary tracks. Med J Aust. 2008;188(3):177-8.

25. Walters L, Worley P, Prideaux D, Lange K. Do consultations in rural general practice take more time when precepting medical students? Med Educ. 2008;42(1):69-73.

26. Tesson G, Curran V, Pong RW, Strasser R. Advances in rural medical education in three countries: Canada, The United States and Australia. Rural and Remote Health 5 [serial on the Internet]. 2005 [cited 2008 Jul 21];397. Available from: http://www.rrh.org.au

27. Nelson J. Rural general practice: a community perspective. National Networks. 2000;(25):9.

28. Stagg P. Future doctors of the Riverland. Chosen by the community, in the community, for the community. National Networks. 2000;(22):8-10.

\section{THE AUTHOR}

Paul Worley (Corresponding Author: paul. worley@flinders.edu.au), Dean of Flinders University School of Medicine and academic director of the Board of the Australian College of Rural and Remote Medicine.

Submitted: June 16, 2008

Approved for publication: September 7, 2008 